\title{
Establishing a public umbilical cord blood stem cell bank for South Africa: an enquiry into public acceptability
}

\author{
${ }^{1,2}$ Madelein Meissner-Roloff, ${ }^{1,2}$ Michael S. Pepper \\ Department of ${ }^{1}$ Immunology, Faculty of Health Sciences, and ${ }^{2}$ Institute for Cellular and Molecular Medicine, \\ University of Pretoria, Pretoria, South Africa
}

The authors have no known conflict of interests, financial or otherwise, that need to be declared.

Address for correspondence

Prof. Michael S. Pepper

Dept. of Immunology

Faculty of Health Sciences

University of Pretoria

P.O. Box 2034

Pretoria 0001

South Africa

Tel: +27 (0)12420 5317

Fax: +27 (0)124203953

E-mail: michael.pepper@up.ac.za

\begin{abstract}
South Africa (SA) faces a large unmet need for bone marrow (BM) transplantation, which could be alleviated in part by establishing a public umbilical cord blood stem cell bank (UCB SCB). Umbilical cord blood is an increasingly utilised source of hematopoietic stem cells for $\mathrm{BM}$ transplantation in addition to BM or mobilized peripheral blood stem cells. Establishing a public UCB SCB would therefore be a positive step towards improving the quality of health care in SA by providing for an important unmet need. This study takes the form of an enquiry into the acceptability of establishing a public bank through an interview with and
\end{abstract}


questionnaire completed by mothers-to-be in the antenatal clinic of a large public hospital in SA. Initial results are positive, with $85 \%$ of the participants in favour of establishing a public UCB SCB in SA. This initial probe will serve as a model for a more comprehensive national enquiry into public support and acceptability in different clinics, hospitals and provinces in SA.

\section{Introduction}

Bone marrow (BM) transplantation has been used successfully for more than 50 years for the treatment of malignant and non-malignant haematological disorders, immune deficiencies and certain genetic disorders (Copelan, 2006). South Africa (SA) faces a large unmet need for BM transplantation, which could be alleviated by establishing a public umbilical cord blood (UCB) stem cell bank (SCB).

Public UCBs are not-for-profit organizations based on voluntary donations. Many professional organizations and national governments support public banking, and its successful application has been extensively documented (Anon, 2006).

The current debate around public vs private UCB banking centres on the fact that commercial banking leads to many ethical dilemmas and - many believe - should thus be avoided (Thornley et al., 2009; Sullivan, 2008). The European Union Group on Ethics'stance against private (otherwise known as "commercial") banking is that it is unethical since it sells a service without any immediate tangible use for therapeutic options (Malgieri et al., 2010; Anon, 2004). Proponents of private banking, on the other hand, claim that individuals have the freedom to choose where to store their UCB units and should not be prohibited from doing so (Jordaan et al., 2009).

The World Marrow Donor Association (WMDA) estimates that "Approximately 70\% of patients with blood disorders such as leukaemia, severe aplastic anaemia and congenital or other acquired disorders will not have a suitable family donor" (Anon, 2006). Siblings have a 1:4 chance of being an adequate match whereas a 1:8 chance exists between a parent and child. However, with an adequate pool of publicly stored UCB units, the likelihood of finding an appropriate HLA-matched allogeneic unit is at least $40 \%$ and increases as the number of 
publicly stored units increases (Anon, 2006).

Although the field of UCB banking is mostly polarised between the two seemingly opposing categories for storing UCB units (public or private), alternative models have been suggested to overcome these differences. It is generally agreed that UCB banks have a role to play in furthering future therapeutic applications of UCB, and that UCB units should be made available to the public. These two principles have given rise to so-called "public-private hybrid UCB banks". There are many different models through which hybrid banks operate, ranging from catering for both public and private banking to banks in which a certain percentage of each stored sample (e.g. 80\%) is available for public access while the remaining sample volume $(20 \%)$ is retained for private use (Jordaan et al., 2009). Hybrid bank models do not necessarily provide a steady solution to the on-going debates and probably contribute more towards current confusion and controversies. However, with advances in cellular therapy such as induced pluripotent stem cell technology and cell expansion and tissue generation, there might be merit in investigating the benefits provided by these hybrid banks in serving the public through both public and private storage of cell products.

It is important to have an intimate knowledge of the benefits provided by each of the abovementioned UCB bank models in order to best provide for the needs of SA citizens. A public UCB bank in SA would give many patients access to previously unavailable treatments by providing a large pool of genetically diverse UCB samples representative of SA demographics. Given SA's genetic diversity and the financial constraints that exist for many of its citizens, there is little dispute that the country could immediately benefit from a public UCB bank.

The study presented here forms part of a larger feasibility study consisting of five components: social acceptability, economic viability, HIV testing, HLA variability and flow cytometry. Results from each of these components will contribute to determining the feasibility of establishing a public UCB SCB in South Africa.

The objective of this study was to assess the extent of public support for the establishment of a public UCB SCB by interviewing mothers attending the antenatal clinic at the Steve Biko Academic Hospital in Pretoria. In addition to assessing public support, we aimed to obtain 
information on potential elements that could impede the establishment of a public SCB. Some of these elements can be overcome and, when appropriately addressed, could have a negligible negative impact on public support for UCB banking. The major areas foreseen that could potentially impact on public support were cultural and religious practices, language constraints, academic insufficiencies and patients' willingness to undergo additional HIV screening.

\section{Methodology}

Using a refined and improved template from the pilot study involving 70 expectant mothers conducted previously (Meissner-Roloff et al., 2012), the current study involved 217 expectant mothers attending the antenatal clinic at the Steve Biko Academic Hospital, who were addressed during a 15-minute interview, following which an anonymous patient questionnaire was completed. Visual aids (a doll with an umbilical cord and placenta and relevant posters) were used to explain concepts relating to UCB banking during the interview. Participants were given the opportunity to raise questions and/or comment during and after the interview and were encouraged to write comments or questions in the space provided for this purpose on the questionnaire itself. The data from the questionnaire was analysed using Microsoft Excel (Microsoft Corp., Redmond, WA) and confidence intervals were calculated with the help of biostatistician, Professor Piet Becker, using the Statistix program (Analytical Software, Tallahassee, FL).

The following six questions were designed to obtain information about patient support for a public UCB SCB and to ascertain each interviewee's understanding of associated UCB SCB processes gained from the interview:

1. If there is a public cord blood bank facility, would they be willing to donate their PLACENTA for medical research? If the participants answered "no" to Q1, they were asked to provide one of the following reasons for not being willing to donate:
a. Religious beliefs
b. Cultural reasons
c. Disagreement about CB bank
d. Afraid of the collection process
e. Not understanding of the reason for setting up a CB bank 


\section{f. Other (please specify)}

2. If the participants answered "no" in question 1, they were asked if they would be willing to donate the BLOOD from the placenta?

3. If they indicated that they were willing to donate the placenta OR just the blood from the placenta and umbilical cord, they were asked whether they would be willing to have their doctor do an additional HIV test.

4. They were asked whether they had heard of stem cells before the interview.

5. They were asked whether they think stem cells could help to treat themselves, their child or somebody else in the future.

6. They were asked whether they think that a public umbilical cord blood stem cell bank is a good idea.

In addition to specific questions relating to UCB banking and stem cells, the questionnaire was designed to collect certain demographic characteristics of the patients. The demographic information that was chosen and the reasons for the choice are as follows:

1. The patient's home language: in order to infer patient ethnicity.

2. Patient age: to investigate whether this could potentially impact the understanding of and support for a public UCB SCB.

3. The number of biological children: to determine whether prior experience with childbirth influences understanding of and support for a public UCB SCB.

4. Marital and employment status: considered to enable inference of the potential influence that these factors might have on the understanding of and support for a public UCB SCB.

\section{Results and Discussion}

Many of the mothers-to-be attending the antenatal clinic at the Steve Biko Academic Hospital represented high-risk pregnancies and were often referred by their local clinics. It could be argued that these mothers had better access to and received more information regarding their pregnancies and might thus have been more educated about their pregnancies than mothers attending other clinics. This could have facilitated the understanding of the information presented to the mothers at this clinic, and it was understood that it might be more difficult to 
convey the same information in rural clinics.

Despite the interviewer's efforts, questions were sometimes left unanswered (BL) which delivered 'non-workable data' (non-useful data). Patients that left some questions unanswered could have done so for various reasons, including the fact that the patients did not understand the question, they were undecided or reluctant to answer (e.g. to undergo an additional HIV test) or were not able to complete the questionnaire because of time constraints (e.g. called by a nurse or doctor).

In order to obtain about 200 questionnaires with workable data a total of 217 patients were interviewed. Fig. 1 gives an overview of all the results obtained (useful and non-useful) for questions one to six (Q1to Q6). Fig. 2 indicates the ratio of useful to non-useful (blank or unanswered) data obtained for each question. It shows that more than $85 \%$ of all the gathered data was useful and could be used for downstream analyses.

Responses to question 1: "If there is a public cord blood bank facility, would you be willing to donate your PLACENTA (afterbirth) for medical research?"

Support for donation of the placenta was measured in Q1 - where $80 \%$ of participants were willing to donate their placenta (Fig.1). In order to infer the reliability of this result, a 95\% confidence interval (CI) was calculated. Using the Statistix software, the interval was calculated as $74.4 \%$ to $85.1 \%$. When results were corrected to use workable data only, the number of patients supportive of Q1 increased to a liberal 85\% (Fig. 3) (95\% CI, [79.9\% to $89.7 \%])$.

Patients unwilling to donate their placenta were asked to provide reasons for their reluctance in order to ascertain whether a particular concern was dominant amongst the group. Patients were provided with a list of potential concerns and were allowed to indicate more than one concern/reason for their reluctance to donate their placenta.

As reported in Fig. 4 the majority of patients (78\% N/A) indicated support for the public bank without indicating any reasons for concern. This corresponds to the $80 \%$ of patients that were willing to donate their placentas in Q1. The discrepancy between Q2's 78\% (Fig. 4 and Q1's $80 \%$ (Fig. 1) can be attributed to two patients that were willing to donate their placenta in Q1 but still gave reasons as to why they might not be willing to donate their placentas. It is unclear why these patients also indicated reasons for unwillingness to donate their placentas and raises the question about the extent to which these two patients understood the 
presentation and subsequent questionnaire questions. Upon investigation of answers provided for the remainder of the questionnaire, although the first patient was willing to donate the placenta and the blood from the placenta, she indicated that donation of the placenta might be against her religion. The remainder of the questionnaire was left unanswered and no definitive conclusions could be made with regard to the patient's understanding of the presentation or banking as a whole. The second patient was willing to donate the placenta but not the blood from the placenta and indicated her reason as "it is sometimes not safe". This patient left Q3 unanswered, but was otherwise supportive of establishing a public UCB SCB.

No specific problematic areas were observed that related to patients' reluctance to donate their placentas. The reasons provided by the $22 \%$ of unsupportive patients were varied and not linked to a specific language group (discussed later). There was an equal amount of concern that donation of the placenta might be against people's religion or culture - $4 \%$ each while $4 \%$ provided their own reasons for their reluctance to donate their placentas (Fig. 4). Only $1 \%$ of people were unsupportive of the idea of a public UCB bank while $2 \%$ were afraid of the collection process. It also seems that everybody understood the reasons provided for establishing a public UCB SCB in SA, since nobody indicated the reason for their reluctance to be an unclear understanding of the motivation for establishing an UCB bank (Fig. 4).

Personal reasons provided by $4 \%$ of the patients were mostly concerned with fears unrelated to reasons provided on the questionnaire. These reasons included: 1) fears that collection procedures could be unsafe; 2) the study overwhelmed the patient and created uncertainty; 3 ) reluctance due to the person's HIV status (2 individuals); 4) the person suffered from epilepsy and was afraid that the blood would not be used for intended purposes; 5) "it is part of somebody's body"; 6) patient was not interested and 7) fear of donation.

These concerns could be addressed by assuring the patients of the safety and efficacy of the UCB collection, banking and redistribution procedures. Once UCB banking becomes common practice, people with these fears might feel less intimidated by the "novelty" of UCB technology while others might become more supportive once the positive effects of UCB transplantation become known in the community after successful treatments.

No inference could be drawn from the results that religious or cultural concerns (related to blood, blood donations etc.) were more prominently associated with a specific language group (or implied ethnic groups) for two reasons. First, results displayed might not hold true for different demographic settings in SA; although the patient cohort was diverse, some 
ethnic groups - who might still have cultural, religious or other objections - were underrepresented. Second, the questionnaire asked the patients to indicate their first language and not their ethnicity culture or religion; in trying to steer clear of any racial insinuations, it was wrongly assumed that language could be a good indicator of the person's ethnicity or culture - which is not the case, as will be discussed later.

For these two reasons it is most likely premature to conclude that religion and culture could not significantly impede the establishment of a public UCB SCB, although the influence of religion and culture in our study cohort seems to be negligible. It is important to consider that their influence might be more pronounced in rural areas where people might adhere more to their customs, or amongst different ethnic groups not adequately represented in our patient cohort.

Unfortunately all of these reasons are conservative estimates for reasons mentioned above since $9 \%$ of the participants left the reasons blank or unanswered, which therefore does not exclude them from not having cultural, religious or other more personal concerns.

\section{Responses to question 2: "If you answered "no" in question 1, would you be willing to donate the BLOOD from your placenta?"}

Patients were requested to answer Question 2 only if (1) they answered "no" to Q1 or (2) if they were of a cultural or religious group that would, under normal circumstances, approach their physician with the request to take the placenta home after birth. This would give an estimate of patients that might support UCB banking, but because of cultural or religious practices involving the placenta, might oppose donation of their placenta. We therefore wished to determine whether these patients - who were unwilling to donate the placenta would be willing to donate the blood from the placenta and thereby still support UCB banking.

All the workable/useful data for Q2 is indicated in Fig. 3. From these results it can be seen that of the initial $15 \%$ of patients who were against donation of the placenta, $2,5 \%$ were willing to donate the blood from the placenta, $12,5 \%$ were not willing and answered "no" to Q2, while $85 \%$ of the participants indicated that this question was not applicable to them (comparing well with results from Q1, Fig. 3).

The 3\% of patients willing to donate the blood from the placenta (who answered "yes" to Q2) can be divided into two groups. Group 1 were patients that left Q1 blank but answered "yes" 
to Q2: this accounts for $1 \%$ of the 3\% who said "yes" to Q2. These patients were willing to donate the blood from the placenta. One of these mothers indicated that it is against her culture to donate the placenta. The second group were patients that answered "no" to Q1 but said "yes" to Q2: this accounts for $1 \%$ of the 3\% who said "Yes" to Q2. One patient (1\%) answered "yes" to Q1 and "yes" Q2, which accounts for the last 1\% of the 3\% who said "yes" to Q2.

This last result could indicate that these patients might want to retain the placenta, but would allow the blood to be collected from the placenta for UCB donation. One patient indicated that her reluctance to donate the placenta was due to her HIV-positive status although this did not influence her decision to donate the blood from the placenta. A misperception encountered a number of times during the patient interview was the belief that blood "outside of the body" does not contain HIV anymore and would thus not be able to infect people. It is probable that this perception arose from misinterpretation of safety guidelines for dealing with HIV. Although it is true that HIV is fragile and does not survive well 'outside of the body' - i.e. when exposed to air, heat or other chemicals - it should clearly be distinguished from collected body fluids - such as donated blood, where the HIV remains viable.

Of the $12,5 \%$ that answered "no" to Q2, $12 \%$ were neither willing to donate the placenta (Q1) nor the blood from the placenta $(\mathrm{Q} 2)$ while the remaining $0.5 \%$ left Q1 unanswered. Upon investigating the reasons for these patients' reluctance, it was found that $3 \%$ of these patients indicated that donation was against their religious belief while $2 \%$ indicated that it was against their culture (Table 1).

Responses to question 3: "If you are willing to donate your placenta OR just the blood from the placenta and umbilical cord, would you be willing to allow your doctor to do an additional HIV test?”

Of all the questions, Q3 was left unanswered most often. Fig. 2 indicates that $85 \%$ of data gathered for Q3 was useful, while 15\% was left blank/unanswered. Fig. 1 illustrates that 78\% of patients were willing to undergo additional HIV testing, 7\% were not and $15 \%$ left the question unanswered. The reasons for the patients' reluctance to answer this question are uncertain. Patients might have been uncertain about the need for a second HIV test since all attending patients at the antenatal clinic in the Steve Biko Academic Hospital had already undergone HIV testing. However, these reasons were clarified during the interview. It is more 
likely that patients might have been fearful of undergoing additional HIV testing. Since mothers presumably know their status because of the previous HIV screening, fears could be related to either being diagnosed as being HIV positive or a fear that their status might have changed from negative to positive. It is also possible that some of these patients weren't comfortable with needles and didn't want to go through the process of testing again while some of the patients could potentially not have been able to complete the entire questionnaire and therefore left this question unanswered. Although much has been done in South Africa to overcome the problems of stigmatisation related to an individual's HIV status, there are still many who hold these views and fears.

When the results were corrected to only look at useful data, $92 \%$ of patients were willing to undergo the additional HIV test, while $8 \%$ were unwilling (Fig. 3).

Since it is a prerequisite to test all UCB prior to banking, a person's refusal to undergo an additional HIV test would result in the donated UCB being discarded. It is therefore important to ask how many of the patients that were willing to donate their placentas (Q1) were also willing to undergo the additional HIV test (Q3). Without taking the unanswered questions into consideration, it was found that $71 \%$ of patients indicated that they were willing to donate their placenta and undergo an additional HIV test.

Responses to question 4: "Have you heard of stem cells before today?" and responses to question 5: "Do you think stem cells can help to treat you, your child or somebody else in the future?"

Question 4 was intended to serve a dual purpose: 1) to verify whether prior knowledge about stem cells and UCB SC banking could influence the patients' readiness to donate and 2) when analysed together with Q5, to be used as a crude measure of the patients' understanding of the concepts discussed in the presentation. In other words, a person that did not know what SCs were before the presentation (Q4) but understood that SCs could be used to treat patients with certain diseases (Q5) after the interview presumably understood the content of the interview.

Fig. 3 illustrates that almost $30 \%$ of patients had heard of SCs before the concept was introduced to them during the interview. This number is surprisingly high and might be due to a misunderstanding of the question. Before starting with the interview, the patients were asked how many knew what SCs were. We observed that far fewer than $30 \%$ of patients 
knew what SCs were, with the true number being closer to $10 \%$ to $15 \%$. It could be argued that some patients with prior knowledge about SCs were reluctant to raise their hands in answer to this question at the onset of the presentation, for fear of being singled out. However, during some of the one-on-one interviews, a misunderstanding of the question was encountered: some patients understood the question to mean "have you heard of stem cells today" and not "BEFORE today". This could mean that patients did not always read the whole sentence or that some might have had trouble comprehending the question, which could be attributed to language constraints.

These problems could be addressed by clarifying the question or by putting it first in the questionnaire and allowing patients to answer it before the start of the presentation.

For a more direct measure of the patients' understanding, this question could in future be phrased to ask for direct feedback e.g. "what are stem cells?" or "what can stem cells do". Given the current language constraints, this might, however, complicate the questionnaire and might only be valuable if the questionnaire and interview could be translated into different languages to facilitate better understanding.

Fig. 3 furthermore indicates that $94 \%$ of patients were of the opinion that SCs can be used to treat people with certain haematological diseases (Q5). This is very encouraging, since at least $70 \%$ of the patients were unaware of SCs before the presentation (Fig. 3, Q4) and did not know anything about their therapeutic application beforehand. It stands to reason then that these patients understood the content of the presentation, which enabled them to answer in the affirmative that SCs can be used therapeutically.

It was assumed that having prior knowledge about SCs would be beneficial to obtaining public support for a SCB. Although this might be true in cases where patients are not thoroughly informed during the informed consent process, it does not seem to significantly impact patient support when adequate information is presented to the patients. The impact of prior knowledge (Q4) on a patient's willingness to donate their placenta (Q1), their understanding of elements presented during the interview (Q5) and support for UCB SC banking (Q6) are illustrated in Fig. 5. This figure highlights the importance of the "informing the patient" component when obtaining informed consent. When patients feel empowered by the knowledge presented and are not pressured into making decisions about concepts that they feel uncertain about, there are seemingly few deterrents to obtaining patient support.

Although a remote possibility in our particular context, it could also be argued that patients 
that had previously heard of SCs might have had their own reservations based on what they had heard. Controversies related to embryonic stem cells (ESCs) are frequently reported in the public media. If these patients had been introduced to controversies related to ESCs, they might have been more reluctant to donate their UCB because of the confusion. This might be a more plausible explanation in countries where the ESC debate has been more pronounced, such as the USA. However, in comparison to the USA, SA has had limited public exposure to the ESC versus adult SC debate, rendering this possibility unlikely.

\section{Responses to question 6: "Do you think that a public umbilical cord blood stem cell bank is a good idea?"}

This question provides direct information regarding the patients' support for the establishment of a public UCB SCB. As mentioned earlier, it could furthermore serve as a crude measure of patients' understanding of the presentation and thus processes related to UCB SC banking.

Together with Q5, these two questions received the most positive responses from the patients, with $94 \%$ (95\% CI [91.3.\% to 97.6\%]) of patients being supportive of establishing a public UCB SCB (Fig. 3, Q6) (a liberal estimate since it does not take blank/unanswered data into account). It should be noted that this result differs from patients that were willing to donate their placentas in Q1, where only $85 \%$ of patients were willing to donate their placentas (Fig. 3). There thus seems to be higher theoretical support for donation than actual support.

This $9 \%$ discrepancy can be attributed to the following reasons: $4 \%$ of these patients indicated that donation was either against their own cultural or religious beliefs $(2 \%$ respectively) but were still supportive of the idea of banking; $2 \%$ indicated that they were afraid of the donation process involved in Q1; 2\% left the reason for their reluctance to donate their UCB blank while the remaining reasons are attributed to personal reasons. Some of these personal reasons indicate that a few patients were unwilling to donate the placenta themselves, although they were theoretically supportive of establishing a public UCB SCB. They indicated reasons such as they would "like to think about it" or were "taken by surprise".

It might be unrealistic to think that $85 \%$ of patients would follow through with their decision to donate the placenta. The questionnaire was theoretical and very little was at stake. Once confronted with the actual informed consent documents, these patients might not all be as 
willing to donate their placentas to medical research. However, results presented here are very encouraging and seem to provide more than sufficient public support for establishing a public UCB SCB, provided that patients are given adequate information in order to make an informed decision.

\section{Other patient information}

A section was included to collect information regarding patient demographics. These demographics included: patients' language, age, number of biological children, their marital and employment status. The influence of each of these demographics is explained below.

\section{Patient language}

In order to obtain an indication of how language constraints influence the patients' understanding of the presentation and their support for UCB banking, patients were asked to indicate their first language.

Although the patient cohort was diverse, many of South Africa's 11 official languages were underrepresented as can be seen in Table 2. One patient from a neighbouring country was French speaking, accounting for the $12^{\text {th }}$ language indicated in Table 2 . This is mostly due to the location at which the study was performed and indicates, therefore, that it needs to be repeated in different provinces throughout SA where different language distributions occur. Of interest is that some patients attending the clinic were from neighbouring countries and had either emigrated to SA or work in South Africa but still retain their nationalities. One patient from North Africa accounts for the French language in Table 2.

Although some useful information could be gathered from the indicated languages and the corresponding answers in the questionnaire, it does not provide a complete picture of the language constraints present. Since filling out the questionnaire was voluntary, there were some patients that were unwilling to fill out the questionnaire. Of these patients, it was evident that some were unable to understand anything during the presentation because they could not understand the language spoken (English). Their English was at best only broken English and these patients would have benefitted most from a translated questionnaire and interview (or a translator). Therefore, results obtained for the influence of patient language on the patients' understanding of the questionnaire is significantly skewed towards patients that were able to comprehend. 
Unfortunately, the initial numbers of patients in the audience and the number of patients that were clearly unable to understand the presentation because of language constraints were not recorded. These elements (audience size vs actual participation) are extremely important parameters that could provide useful information about public understanding and subsequent support. These elements need to be added to the final protocol if used in a national survey of patient support of a UCB SCB.

Fig. 6 illustrates how language could potentially impact a patient's understanding of the presentation. It should also be noted that it does not account for patients that could not participate in the questionnaire because of a complete lack of understanding. Therefore, these numbers are an overestimate of the true situation. Many language groups were underrepresented. Fig. 6 illustrates the proportional relationship of the most frequently encountered languages to the patients' understanding of the questionnaire (Q5), while the more rarely encountered languages were grouped together under "Other".

To facilitate a better understanding of the interview and questions in the questionnaire, discussions among attending patients were encouraged. Often, a patient with sufficient English comprehension would translate the patients' queries back to the interviewer and vice versa in order to facilitate a better understanding between patient and interviewer. However, it must be assumed that most of the patients that completed the questionnaire had at least a fair understanding of English or Afrikaans (the two languages spoken by the interviewer and used to clarify concepts and answer questions).

Results illustrated in Fig. 6 seem to indicate that language does not significantly impede approval for the establishment of a public UCB SCB. This is, however, an overestimation and confirms the importance of properly addressing the issues concerned in UCB banking through easily accessible language understandable to all patients. This we feel will be the single most important defining factor in influencing patient support throughout SA for the establishment of a public UCB SCB.

\section{Language is not an adequate indicator of ethnicity or culture}

As mentioned previously, we wrongly assumed that language could simultaneously provide information regarding a patient's understanding of the questionnaire, as well as serve as a good indicator of a person's ethnicity or culture. This is unfortunately not always the case; e.g. an Italian (ethnicity) born in SA would probably speak English (language), thus this mistake renders information regarding patient ethnicity insufficient. 
Although it holds true that sometimes a person's first language could be an indication of their ethnicity, it was found that many South African mothers to be customarily adopt the language spoken by the husband as their home language. Patients might have indicated this home language instead of their own first language. Home language, therefore, may have no relation to people's ethnicity and states nothing about their culture. Thus, if the husband speaks Zulu and the patient Pedi, their home language would most likely be Zulu while the patient's ethnicity could be Pedi. Furthermore, many African patients often speak more than one African language and in some cases neither husband nor wife speaks their partner's first language. In these situations they communicate in a second language that subsequently becomes the home language.

Therefore all inferences about relationships based on language groups (as a substitute for ethnic or cultural groups) are at best a crude indicator of the influence of ethnicity on patient support and understanding of UCB banking. As an example, if $23 \%$ of patients indicate that they speak English it does not indicate whether these patients were Caucasian English- or Afrikaans-speaking patients, whether they were of Coloured, Indian or African origin. While 52 of the patients were Afrikaans speaking, at most half of these were Caucasian (investigator observation) while the rest constituted Coloured and only a few African patients. In contrast, very few Caucasian English-speaking patients took part in the study, while the majority of the 52 English-speaking patients were of Indian or African origin (investigator observation) (Table 2).

It will be important to establish women's cultural practices in relation to body waste (i.e. placenta) in pregnancy, as well as to tissues, blood and donation or "banking". Therefore, suffice it to say that more accurate and in-depth information regarding patient ethnicity, culture and religion needs to be obtained. Without this, no conclusions can be drawn about cultural or religious practices related to certain ethnic groups or more support for UCB banking from specific ethnic groups.

\section{Influence of patient age on support for a public UCB SCB}

From observations made during the pilot study (which preceded the current study), younger patients seemed to be more supportive of UCB banking than older patients (Meissner-Roloff et al., 2012). In order to better quantify this observation, the questionnaire was revised to make provision for annotating patient age.

The majority of patients that attended the clinic and took part in the survey were between the 
ages of 26 and 30 (Table 2). However, when patients were grouped into "younger" (ages 1830) and "older" (ages 31+) groups, the numbers were almost equal, with 112 younger patients and 93 older patients (the remaining 12 patients did not indicate their age). Results, corrected for the number of patients per age group, are indicated in Fig. 7 and show how a patient's age affected her willingness to donate her placenta (Q1) and her support for a public UCB SCB (Q6).

Of the younger patients, 81\% indicated their support for both Q1 and Q6, while 70\% support was obtained from the older patients. Assessing each question individually, younger patients were more willing to donate their placentas (84\%) than older patients $(77 \%)$ and younger patients were generally more supportive of the idea of establishing a public UCB SCB (92\%) than older patients (82\%) (Fig. 7).

To establish whether this observed difference in support between the age groups could be due to a difference in understanding the presentation, the patients' ages were compared to their understanding of the questionnaire (Q5) (results not shown). It was found that $90 \%$ of the younger patients understood the information presented and thought that SCs could be used to treat people with certain disorders. The older group's understanding (81\%) corresponds well with their willingness to support the bank $(82 \%)$ and could potentially imply that their weaker comprehension had a greater impact on their support than for the younger group with better comprehension. Other possible reasons that could explain greater support from younger patients include: 1) that younger patients have been more exposed to the latest technology. As a consequence, they might be more open to acceptance of new technological concepts, might be less intimidated by these concepts and more keen to explore new areas of innovation; 2) younger patients could be better equipped (schooling and thus comprehension) than their predecessors; 3 ) older generations could potentially be more reluctant to participate because of beliefs shaped by previous political regimes.

However, most patients that took part in the study seemed to adequately understand the presentation regardless of their age. It seems that the determining factor for obtaining support is to equip the patients with adequate and accessible information in order for them to make a properly informed decision. This information should be tailored to address not only people with different levels of schooling, but should also be 'age friendly'; i.e. should accommodate older people's lack of understanding of technological development and comprehension.

The influence of exposure to childbirth on patient support 
Another factor that could influence a patient's understanding of UCB banking and related processes (discussed during the presentation) could be a patient's prior exposure to childbirth. During the pilot study (Meissner-Roloff et al., 2012), it was observed that several of the patients were unsure of the nature of the placenta. The word was subsequently translated in order to clarify its meaning but some patients were still unsure of the placenta's role during pregnancy and its normal disposal after pregnancy. It was therefore thought that a patient who had gone through the process of childbirth would know what to expect, understand more, be less afraid of donation and would subsequently be more supportive of a public bank. Table 2 illustrates the number of children born to mothers of different age groups.

Patients were grouped into two categories: patients with biological children and patients without biological children. There were 54 patients without any children and most of these (45) were below the age of 30 . When comparing support from these two groups (with and without children), it appears that patients without children are slightly less supportive of establishing a public UCB SCB.

At first glance, this might seem to contrast with an earlier observation made i.e. where younger patients were found to be more supportive of establishing an UCB SCB vs. patients with more children (i.e. older patients) that showed more support for an UCB bank. However, this is a feature of the subgroupings considered in this case. For example, the number of older patients that had children and were supportive of UCB banking was $75 \%$ (63 out of 83 patients over the age of 30 ) as opposed to $84 \%$ of younger mothers with children (54 out of 64 patients under the age of 30 ). However older and younger patients with children were grouped together in comparing the influence of prior exposure to childbirth. Thus the weight of the results seen in Fig. 8 is carried by the younger supportive population that also had prior exposure to childbirth.

Furthermore, the number of older mothers without children was much less than younger mothers without children ( 9 as opposed to 45 respectively). Thus despite the fact that $48 \%$ of younger mothers have not had exposure to childbirth, $81 \%$ under the age of 30 were still supportive of establishing an UCB bank. This is in contrast to 7\% of older mothers who had no children of whom only $70 \%$ (over the age of 30 ) were supportive of establishing an UCB - accounting for the results seen in Fig. 7.

Results illustrated in Fig. 8 reveal that $84 \%$ of patients without children were willing to donate their placenta (Q1), 90\% of them thought that SCs could be used to treat patients (Q5) 
and $90 \%$ thought that building a public UCB SCB was a good idea (Q6). Patients with children responded similarly but with somewhat greater support shown in their answers, with $85 \%$ of patients being willing to donate the placenta (Q1), 95\% understanding the application of SCs (Q5) and 96\% thinking that establishing a public UCB SCB was a good idea.

Collectively, all three questions relating to support and understanding of a public UCB SCB (Q1, Q5 and Q6) indicated 80\% support from patients without children and 85\% from patients with children. In each case, it seems that having gone through the experience of childbirth (or previously being exposed to it) slightly aids the patient's understanding of the concepts involved in UCB banking - e.g. what the placenta is; what it does during pregnancy; that it is discarded after pregnancy, etc. These patients might subsequently be less fearful of the unknowns associated with UCB collection than patients without childbirth experience. Nevertheless, the results are very similar between the two groups and the differences are not statistically significant. Although childbirth exposure could potentially influence patients' support and understanding of UCB banking, it is unlikely to significantly impede support for the establishment of a public UCB SCB.

\section{Marital and employment status}

These two parameters provide personal information about patients by shedding light on their current circumstances and potential support structures. The possible relationships between marital status, employment status and patient support are far too numerous to be adequately analysed with the few parameters provided by this survey. However, they could be used as initial probes into whether marital or employment status has any impact on patient support at all, which could merit a more comprehensive analysis of potential contributing factors for each category.

Table 2 indicates that the majority of patients (47\%) were married (M), followed by $44 \%$ unmarried patients (U). The remaining patients were either widowed (W) (1\%), divorced (D) $(2 \%)$ or left the category unanswered $(\mathrm{BL})(6 \%)$.

Information gathered on patient employment is illustrated in Table 2. It indicates conservative estimates of $48 \%$ unemployment (U) and $31 \%$ employment (E), since $21 \%$ of patients left the question unanswered (BL).

Patients' answers to Q1 and their corresponding employment status and marital status are displayed in Fig. 9. From this data it seems that patients were supportive of establishing a public SCB regardless of whether they were married, unmarried, employed or unemployed. 
Blank data (unanswered Q1) is removed and the remaining data is corrected to display percentage support proportional to the number of patients per category; i.e. 68 patients were employed, with 57 of them supportive (Q1), thus $84 \%$ of employed patients are supportive of public UCB SC banking.

From Fig. 9 it is clear that marital status and employment status are not determining factors for a patient's support for UCB banking. Equal support was given by married (78\%) and unmarried $(75 \%)$ patients $-84 \%$ of employed people supported the bank and $83 \%$ of unemployed people supported the bank. A similar trend is observed for unsupportive patients in each of the abovementioned categories.

This could result because very little is required of a patient in order to donate their placentas to UCB collection. If they are presented with adequate information, they would not have a need to contact family or relatives for more information or support in making the decision to donate. Furthermore, eligibility for donation does not require any financial contribution nor does a patient have any additional expenses associated with donation, since the placenta and UCB are collected at the time of delivery of the child.

\section{Conclusion}

South Africa is in a favourable position to implement new avenues for access to health care and to increase development in the areas of cellular, molecular and regenerative medicine. Not only are many South Africans in need of these advanced medical and technological developments, but they are also enthusiastic about building a better SA.

Similar studies to the one presented here have been conducted globally. Results from this study are strikingly similar to results obtained from these studies abroad and are discussed below.

1. Fernandez et al (2003) assessed the knowledge and attitudes of Canadian women with regard to testing, collection and banking of UCB SCs. Rucinski et al (2010) reported on the opinions and beliefs of Hispanic and non-Hispanic woman with regard to UCB donation and banking. Both studies encountered a large gap in information available and accessible to patients, with very few patients being aware of UCB banking. As many as $70 \%$ of patients indicated poor or very poor knowledge of UCB SCs (Fernandez et al., 2003) which corresponds to data gathered for this study (Fig. 3, Q4) 
while Katz et al (2010) reported that $79 \%$ of woman lacked basic knowledge about SCs. In the current study it was concluded that educating the public with regard to UCB banking and its application would be the single most important factor in generating public support for a public UCB bank. Rucinski et al (2010) concluded the same, reporting that their biggest barrier to patient support was a lack of basic information available to the public with regard to UCB banking, UCB harvesting and use. The authors furthermore suggested that patients should not only be informed on the social value of UCB banking but also be informed about the technical factors involved in banking.

2. Similar to observations reported in the current study, Fernandez et al (2003) and Katz et al (2011) both reported a majority support for public UCB banking (as opposed to private or hybrid banking). In this study it was found that a conservative estimate for support from patients for the public bank lies between $80 \%$ and $86 \%$ (Fig. 1, Q1 and Q6). Taking only workable data into account, these numbers increase to between $85 \%$ and 94\% (Fig. 3, Q1 and Q6). Similarly, Fernandez et al (2003) reported that $86 \%$ of their Canadian patients opted to store their UCB in a public bank and Katz et al (2011) reported $89 \%$ of patients (from 5 European countries) would store their UCB, $76 \%$ of whom would store publicly.

Additional factors presented in previously published studies that are similar to results from this study.

1. Katz et al (2011) found no correlation between patient income and the decision to donate UCB, which held true for all five countries surveyed. Although information gathered about patient employment in the current study is insufficient to draw definitive conclusions, preliminary data seem to correspond with results obtained for patient income from Katz et al (2011).

2. Many studies have reported on ambiguity of words that caused confusion amongst the patients - most notably "donation" versus "banking", "cord" as explained in "cord blood" (as opposed to spinal cord) (Rucinski et al., 2010). Similarly, the pilot study preceding this study (Meissner-Roloff et al., 2012) found words such as "placenta", and "bank" often confused patients. In order to clarify the concepts, words were either translated (e.g. "placenta" translates to "Inghubo" in Zulu) or explained in broader detail. 
3. Rucinski et al (2010) mentioned that racial and ethnic disparities were observed for donation of UCB similar to those found in organ and tissue donation. Although this does not seem to be the case in South Africa, the possibility that certain ethnic groups in South Africa might be more reluctant to donate cannot conclusively be ruled out in the current study. In order to address potential ethnic influences with regard to UCB banking, the patient cohort would need to be more representative of the population. The questionnaire should also be modified to capture patient ethnicity more accurately.

4. Rucinski et al (2010) also reported on misconceptions with regard to the placenta, its function during pregnancy and what happens to it after pregnancy. This is similar to observations made during the pilot study (Meissner-Roloff et al., 2012) accounting for the lack of patient knowledge on even basic biological concepts.

This study was conducted to estimate public preparedness and support for establishing a public UCB SCB in South Africa. It also obtained information on specific parameters that could potentially impede the establishment of such a bank. Although the patient cohort was not adequately representative of the total population of South Africa, patients were nevertheless optimistic about the potential establishment of a public bank. Comments received from patients during the study were predominantly positive, stating their enthusiasm and support for an UCB bank. Reasons from unsupportive patients were mostly reflective of unavailable and inadequate information available to the public with regard to UCB donation. Patients were supportive of UCB banking regardless of their age, ethnicity, employment, marital status or whether they had previously experienced childbirth. Some of these factors (e.g. previous childbirth) might, however, influence the level of a patient's understanding of UCB donation.

The main determining factor in obtaining support for UCB banking in SA is thus equipping patients with adequate and accessible information in order for them to make a properly informed decision. This information should be tailored to address not only people with different levels of education but should also be 'age friendly'; i.e. should accommodate older people's disadvantage with regard to technological development and comprehension. It should be translated into the different languages of the population, and should include technical factors involved in the processes of UCB donation, banking and application, as well as the social value of donation. Finally, results obtained from this study are supportive of 
establishing a public UCB SCB for SA but should be confirmed in different provinces across the country. The study serves as a preliminary screening of the public response from SA citizens to the acceptability of UCB public banking and paves the way for an in-depth social scientific enquiry.

\section{Acknowledgements}

This work was supported by the Medical Research Council of South Africa. The authors would like to thank Prof. Tessa Marcus and Dr. Hennie Lombaard for their valuable contributions to this work.

\section{References}

1. ANON. 2004. Opinion of the European group on ethics in science and new technologies to the European commission No 19, 16th March 2004.

2. ANON. 2006. WMDA Policy Statement on the Utility of Autologous or Family Cord Blood Unit Storage: pp1-8.

3. COPELAN, E. A. 2006. Hematopoietic Stem-Cell Transplantation. New England Journal of Medicine, 354:1813-1826

4. FERNANDEZ, C.V., GORDON, K., HOF, M.V.D., TAWEEL, S., \& BAYLIS, F. 2003. Knowledge and attitudes of pregnant women with regard to collection, testing and banking of cord blood stem cells. Canadian Medical Association Journal (CMAJ), 168(6):695-698.

5. JORDAAN, D., WOODROW, C., PEPPER, M.S. 2009. Banning private stem cell banks: a human rights analysis. South African Journal on Human Rights, 25(1):126-151.

6. KATZ, G., MILS, A., GARCIA, J., HOOPER, K., MCGUCKIN, C., PLATZ, A., REBULlA, P., SALVATERRA, E., SCHMIDT, A.H., \& TORRABADELLA, M. 2011. Banking cord blood stem cells: attitude and knowledge of pregnant women in five European countries. Transfusion, 51:578-586.

7. MALGIERI, A., KANTZARI, E., PATRIZI, M.P., \& GAMBARDELLA, S. 2010. Bone marrow and umbilical cord blood human mesenchymal stem cells: state of the art. Clinical and Experimental Medicine, 3(4):248-269. 
8. MEISSNER-ROLOFF, M., YOUNG, W., RANGAKA, I., LOMBAARD, H., DHAI, A., TSOTSI, N., \& PEPPER, M.S. 2012. Pilot social feasibility study for the establishment of a public human umbilical cord blood stem cell bank in South Africa. Stem Cell Reviews and Reports, DOI: 10.1007/S12015-012-9390-7.

9. RUCINSKI, D., REYES, B., TIDWELL, L., PHILIPS, R., \& DELVES, D. 2010. Exploring opinions and beliefs about cord blood donation among Hispanic and nonHispanic black woman. Transfusion, 50:1057-1063.

10. SULlIVAN, M.J. 2008. Banking on cord blood stem cells. Nature Review Cancer, 8:555-63.

11. THORNLEY, I., EAPEN, M., SUNG, L., LEE, S.J., DAVIES, S.M., Joffe, S. 2009. Private cord blood banking: experiences and views of pediatric hematopoietic cell transplantation physicians. Pediatrics, 123:1011-1017.

12. TRIPP, A., BANERJEE, P., SIEBURG, M., Planelles, V., LI, F., \& FEUER, G. 2005. Induction of cell cycle arrest by human t-cell lymphotropic virus type 1 tax in hematopoietic progenitor $\left(\mathrm{cd} 34^{+}\right)$cells: modulation of p21cip1/wafl and p27kip1 expression. Journal of Virology, 79(22):14069-14080. 


\section{Legends to Figures}

\section{Figure 1}

Summary of results obtained from questions 1-6 of the questionnaire. Answers were either indicated as "Y" (yes) - indicated by the blue bars; "N" (no) - indicated by red bars; "BL" (left blank) - indicated by green bars or "N/A" (not applicable) - indicated by purple bars. *Note: All selected Q1 Reasons were considered as a positive response and therefore categorised under "Yes", to illustrate that reasons were provided as opposed to being left blank or "N/A".

\section{Figure 2}

All answered questions were deemed 'workable data' or 'useful' and are represented above for questions 1 through 6 (Q1-Q6). Workable (useful) information (blue bars); blank or "Not useful information" (red bars).

\section{Figure 3}

Summary of useful information obtained from questions 1 through 6 (Q1 to Q6). Questions answered by "Y" (yes) are indicated by blue bars; "N" (no), indicated by red bars and "N/A" (not applicable) indicated by purple bars.

\section{Figure 4}

Question 1 Reasons: Patients' reasons why they would not support a public UCB SCB. Patients that answered "no" to Q1 were asked to indicate why there were reluctant to donate their placentas. The following options were provided: Religious beliefs (dark blue bar); Cultural reasons (red bar); Disagreement about CB bank (green bar); Afraid of the collection process (purple bar); Not understanding of the reason for setting up a CB bank (turquoise); and Other (orange bar). Unanswered "Reasons" - (left blank) are indicated by the light blue bar. Patients that answered "yes" to Q1 were instructed to write "N/A" (not applicable) (pink bar).

\section{Figure 5}

Illustration of how prior knowledge about stem cells influences patient willingness to donate the placenta (Q1) (red bar); their understanding of the presentation (Q5) (green bar); and their support for a public bank (Q6) (blue bar). 


\section{Figure 6}

The influence of language on the patients' understanding of the questionnaire (Q5)

\section{Figure 7}

The influence of age on the support for establishing a public UCB SCB. Patient ages were grouped into two groups: "Younger" between the ages of 18 and 30 indicated by the blue bars, and "Older", above the age of 30, indicated by the red bars. Q1 tests a patient's willingness to donate the placenta, while Q6 tests the patient's support for establishing a public UCB SCB.

\section{Figure 8}

The influence of exposure to childbirth on patient's understanding and support for UCB banking. Results displayed indicate positive answers ("yes") to Q1, Q5 and Q6 for patients with children (red bars) and without children (blue bars) respectively.

\section{Figure 9}

The influence of employment and marital status on patient support for a public UCB SCB (Q1). 


\section{Table 1}

Reasons why patients were reluctant to donate either the placenta or the blood from the placenta

$\left.\begin{array}{|l|l|}\hline \text { Q1 Reason for not donating placenta } & \text { Number of patients indicating each reason } \\ \hline \text { Against religious belief } & 6(3 \%) \\ \hline \text { Against culture } & 4(2 \%) \\ \hline \text { Bank is not a good idea } & 1 \\ \hline \text { Afraid of the collection process } & 4(2 \%) \\ \hline \text { Don't understand reason for the bank } & \begin{array}{l}1 \text { (Want to think about it) } \\ \text { Other }\end{array} \\ 1 \text { (HIV status) } \\ 1 \text { (Nlacenta is a part of somebody's body) }\end{array}\right] 2 \%$

Note: Patients could provide more than one reason 


\section{Table 2}

Summary of demographic information of participants.

For each age range, the number of participants, their respective marital and employment statuses, the language distribution as well as the number of previous children is indicated.

\begin{tabular}{|c|c|c|c|c|c|c|c|c|c|c|c|c|c|c|c|c|c|c|c|c|c|c|c|c|c|c|c|c|c|}
\hline \multicolumn{2}{|c|}{ Age Distribution } & \multicolumn{5}{|c|}{ Marital Status* } & \multicolumn{3}{|c|}{ Employment status** } & \multicolumn{13}{|c|}{ Language distribution*** } & \multicolumn{7}{|c|}{ Number of Previous children } \\
\hline Age Range & $\begin{array}{l}\text { Number of } \\
\text { Patients }\end{array}$ & M & w & D & u & BL & E & $\mathbf{u}$ & BL & E & A & $x$ & $\mathrm{~N}$ & z & Tsw & s & Sw & P & v & NS & Tso & $\mathbf{F}$ & 0 & 1 & 2 & 3 & 4 & 5 & BL \\
\hline $18-20$ & 11 & 2 & 0 & 0 & 8 & 1 & 0 & 9 & 2 & 5 & 2 & 0 & 1 & 1 & 1 & 1 & 0 & 0 & 0 & 0 & 0 & 0 & 8 & 2 & 1 & 0 & 0 & 0 & 0 \\
\hline $21-25$ & 35 & 8 & 1 & 0 & 26 & 0 & 11 & 21 & 3 & 7 & 12 & 1 & 2 & 2 & 1 & 1 & 2 & 4 & 3 & 0 & 1 & 0 & 16 & 12 & 5 & 0 & 0 & 0 & 2 \\
\hline $26-30$ & 66 & 33 & 0 & 3 & 27 & 3 & 18 & 35 & 13 & 14 & 23 & 0 & 8 & 6 & 4 & 3 & 0 & 6 & 1 & 1 & 1 & 0 & 21 & 23 & 15 & 4 & 2 & 0 & 1 \\
\hline $31-35$ & 42 & 28 & 1 & 1 & 10 & 2 & 13 & 19 & 10 & 16 & 6 & 0 & 2 & 7 & 2 & 1 & 2 & 9 & 0 & 0 & 0 & 0 & 5 & 18 & 11 & 3 & 4 & 1 & 0 \\
\hline $36-40$ & 41 & 23 & 0 & 0 & 17 & 1 & 22 & 11 & 8 & 8 & 5 & 2 & 4 & 3 & 3 & 6 & 0 & 3 & 2 & 3 & 1 & 1 & 3 & 16 & 11 & 6 & 5 & 0 & 0 \\
\hline $41-45$ & 6 & 3 & 0 & 1 & 2 & 0 & 0 & 6 & 0 & 1 & 4 & 0 & 0 & 1 & 0 & 0 & 0 & 0 & 0 & 0 & 0 & 0 & 1 & 1 & 2 & 0 & 1 & 1 & 0 \\
\hline $46-50$ & 4 & 3 & 0 & 0 & 1 & 0 & 2 & 1 & 1 & 1 & 0 & 0 & 0 & 1 & 0 & 0 & 0 & 1 & 0 & 0 & 1 & 0 & 0 & 1 & 0 & 0 & 1 & 1 & 1 \\
\hline Blank & 12 & 1 & 0 & 0 & 4 & 7 & 1 & 2 & 9 & 1 & 4 & 0 & 1 & 1 & 1 & 1 & 2 & 0 & 1 & 0 & 0 & 0 & 2 & 3 & 1 & 0 & 0 & 0 & 6 \\
\hline Percentages & 217 & 47 & 1 & 2 & 44 & 6 & 31 & 48 & 21 & 24 & 26 & 1 & 8 & 10 & 6 & 6 & 3 & 11 & 3 & 2 & 2 & 0 & 26 & 35 & 21 & 6 & 6 & 1 & 5 \\
\hline${ }^{*}$ Marital Status & $\begin{array}{l}\text { egend: } \mathrm{M}=\mathrm{Ma} \\
\text { tatus Legend: }\end{array}$ & $\begin{array}{l}\frac{i e d ; \mathrm{V}}{\mathrm{E}} \\
=\mathrm{Emp}\end{array}$ & $\begin{array}{l}N=W \\
\text { ployed }\end{array}$ & $\begin{array}{l}\text { dow } \\
U=\end{array}$ & $\begin{array}{l}\text { ed; D } \\
\text { Unem }\end{array}$ & $\begin{array}{l}\text { Divor } \\
\text { Doye }\end{array}$ & $\begin{array}{l}; U=L \\
L=B l a\end{array}$ & rived & Blank & & & & & & & & & & & & & & & & & & & & \\
\hline
\end{tabular}


Figure 1

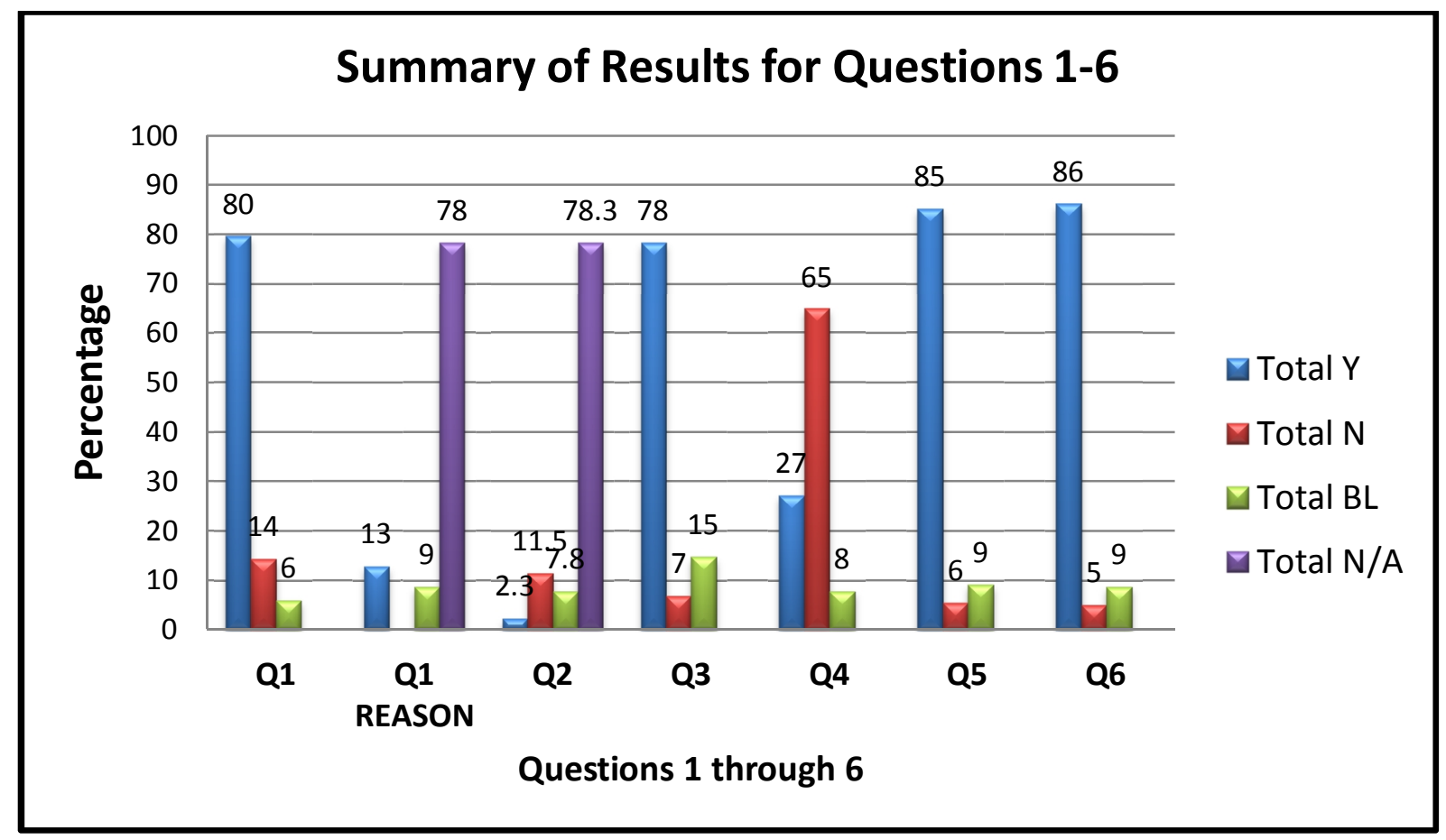


Figure 2

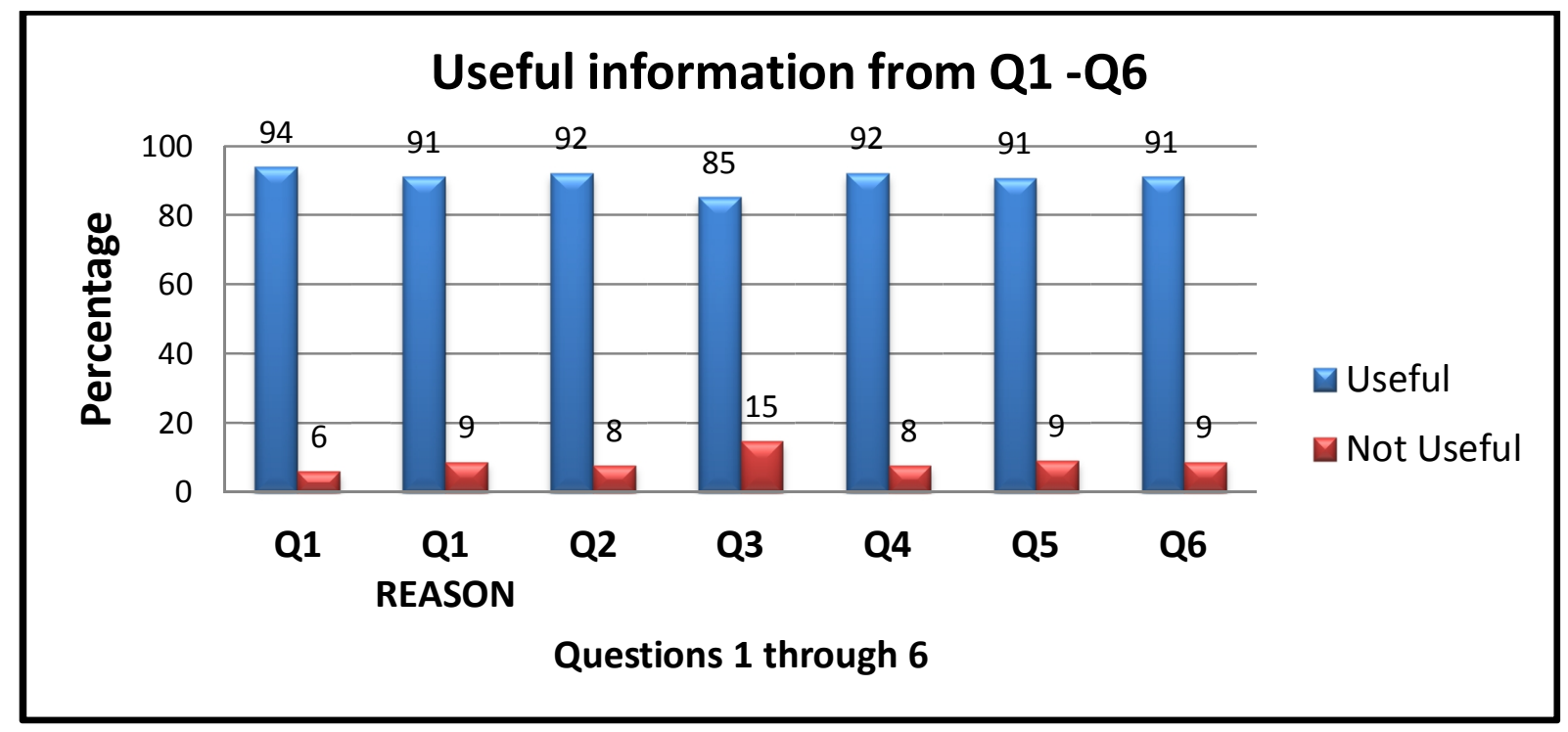


Figure 3

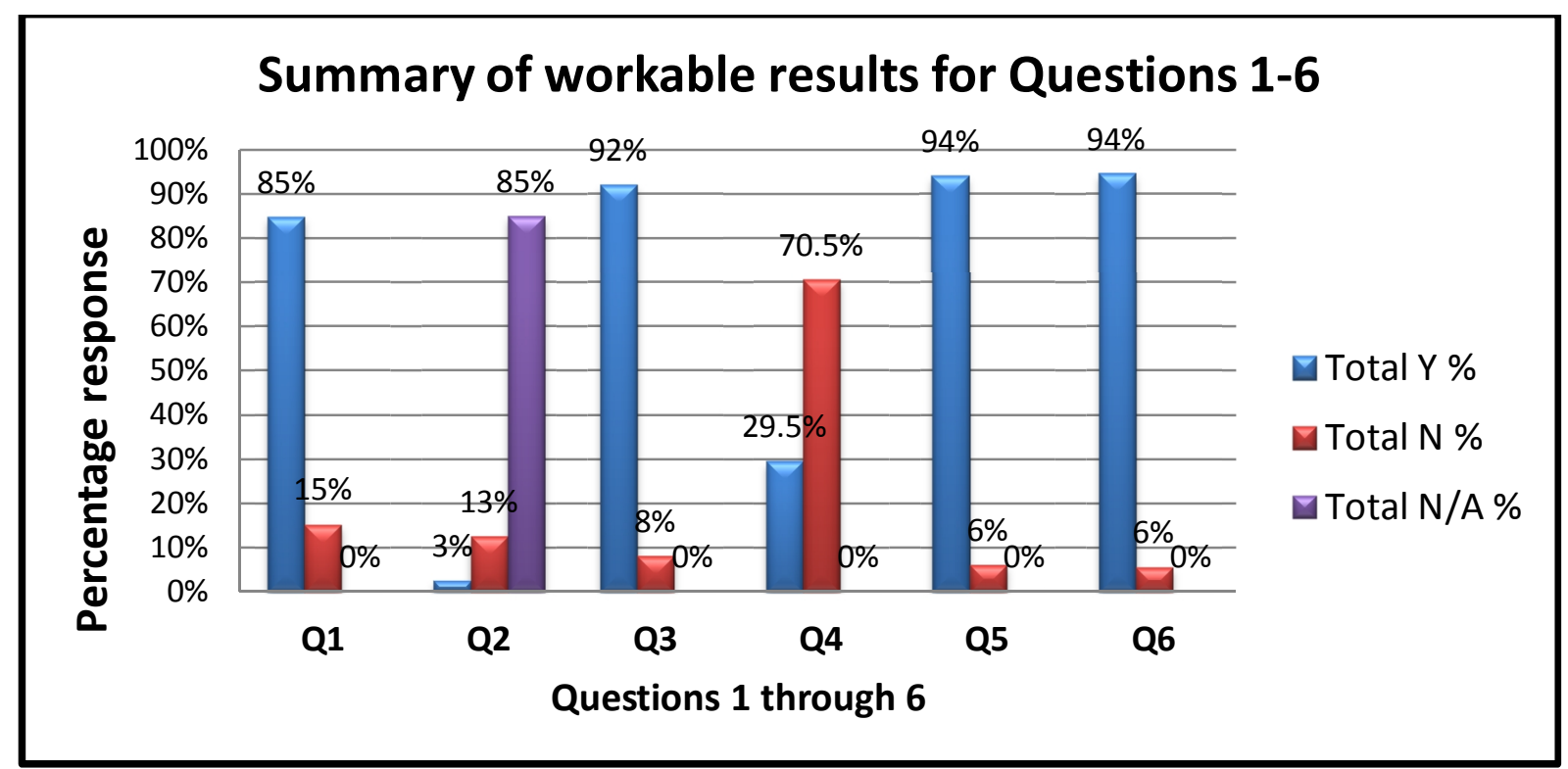


Figure 4

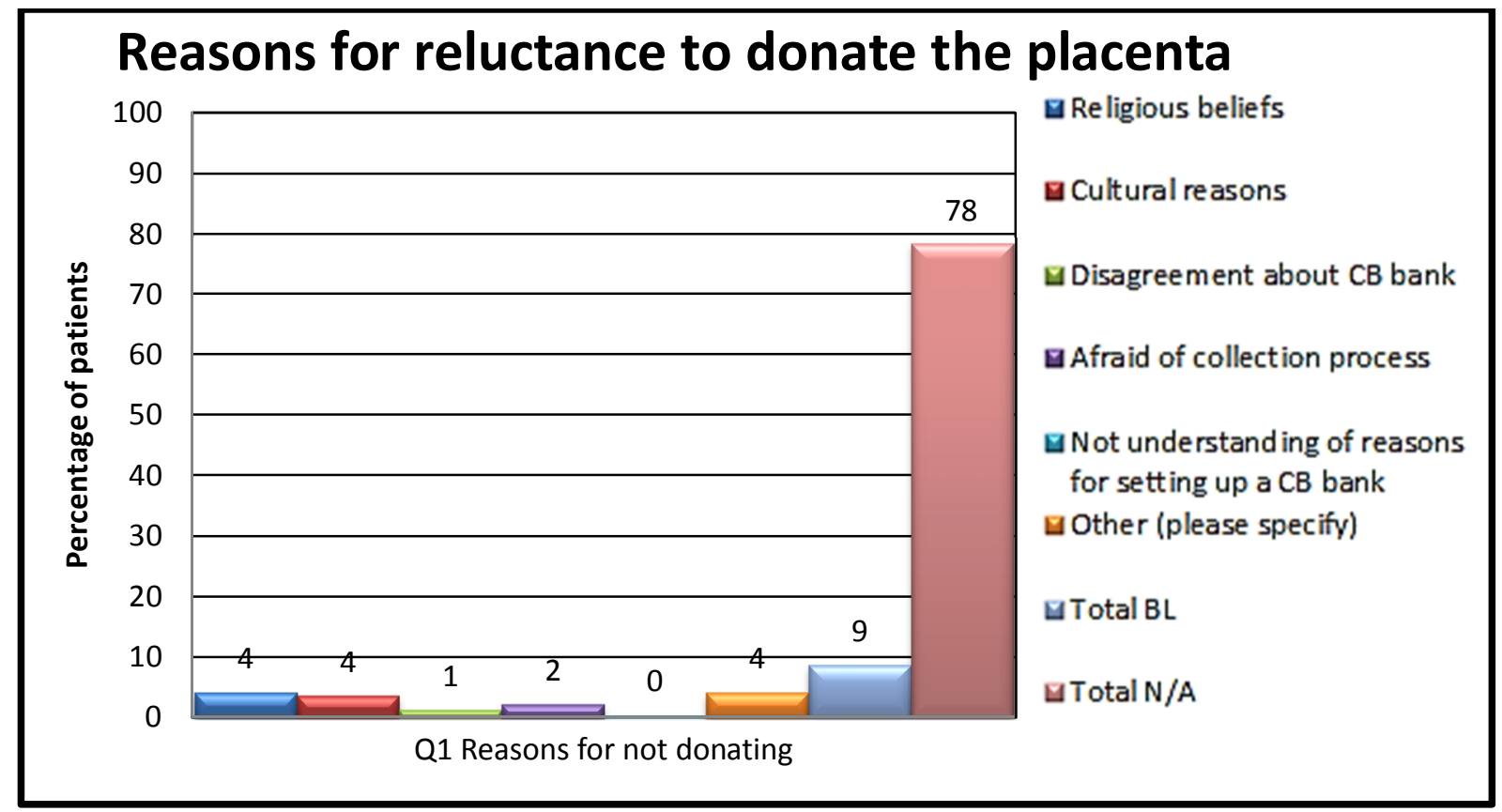


Figure 5

\section{How prior awareness of SCs influences patient} support

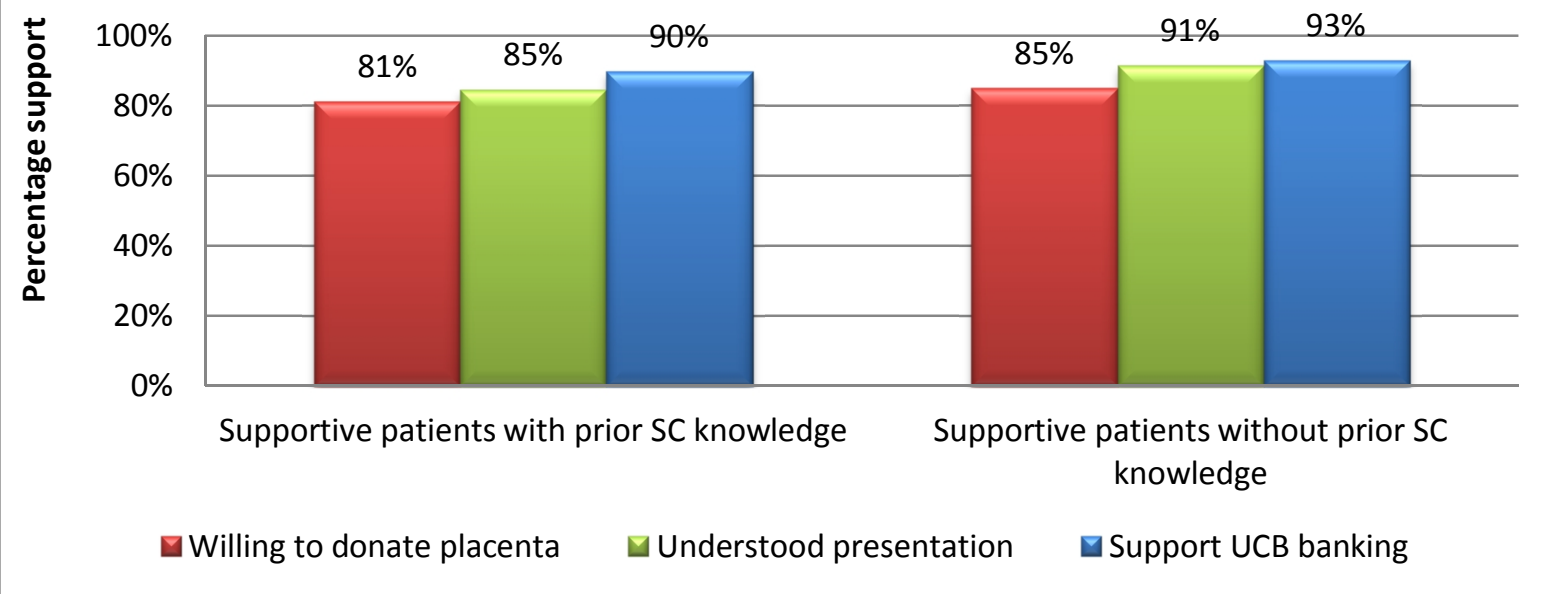


Figure 6

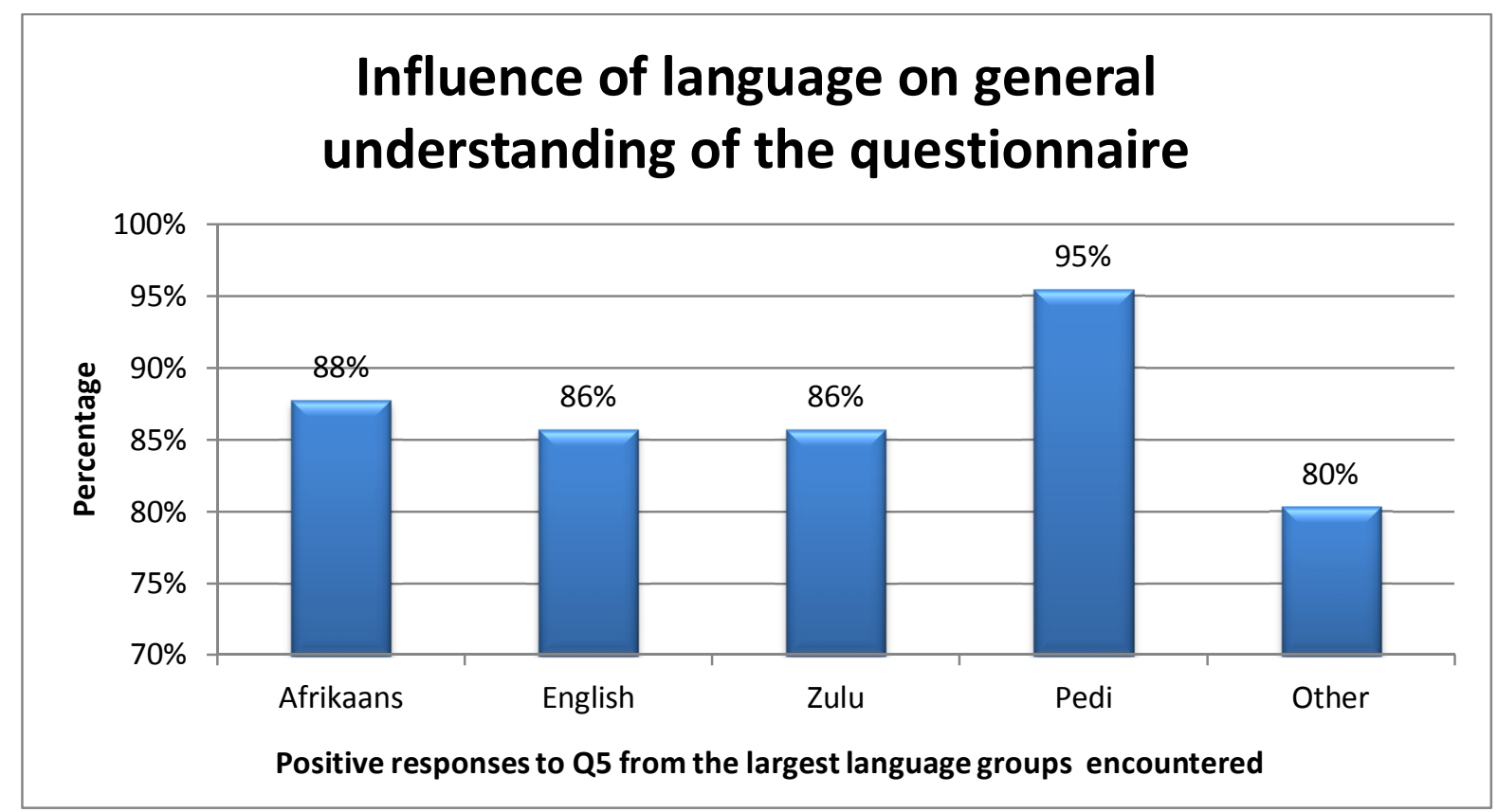


Figure 7

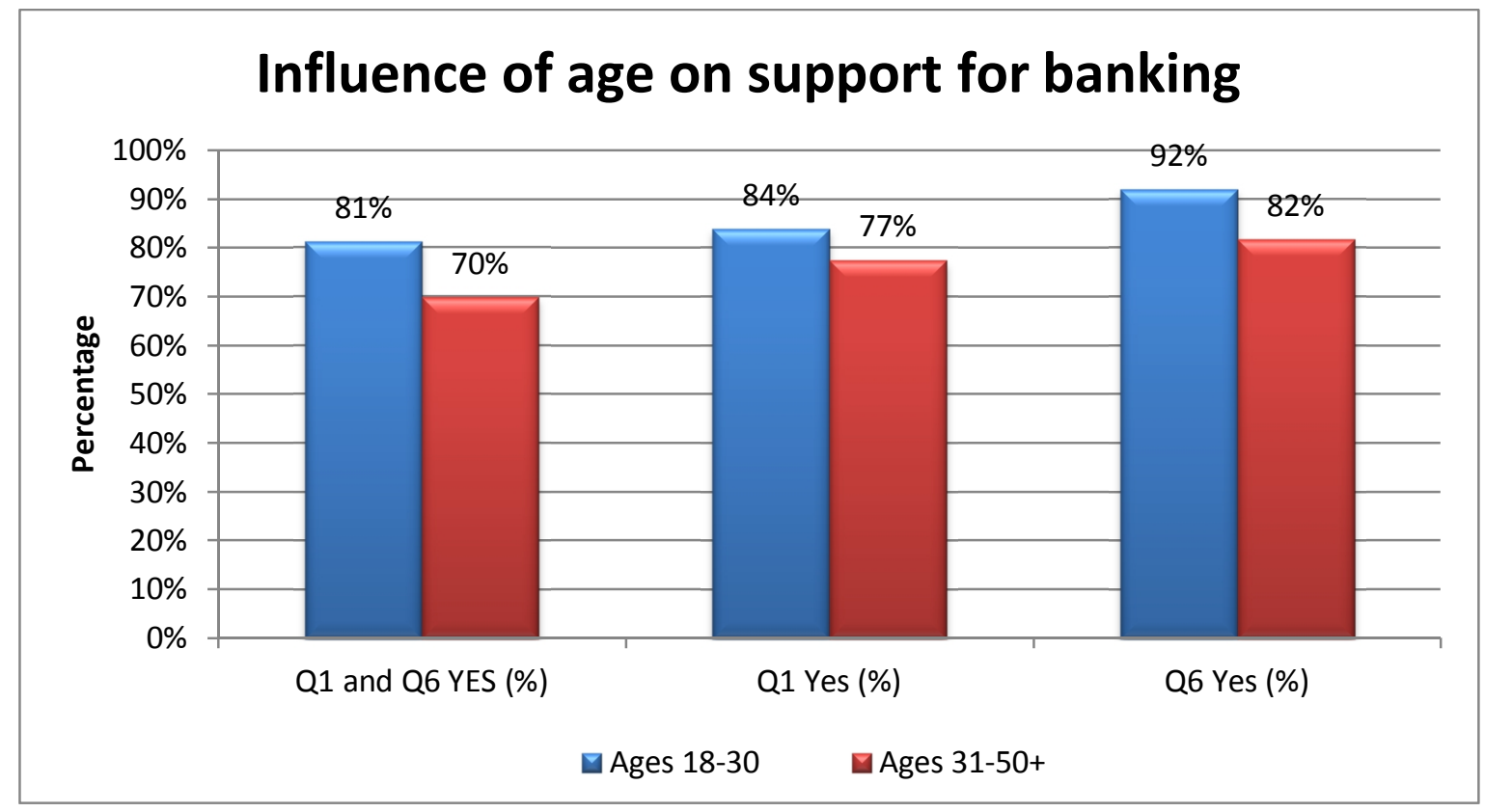


Figure 8

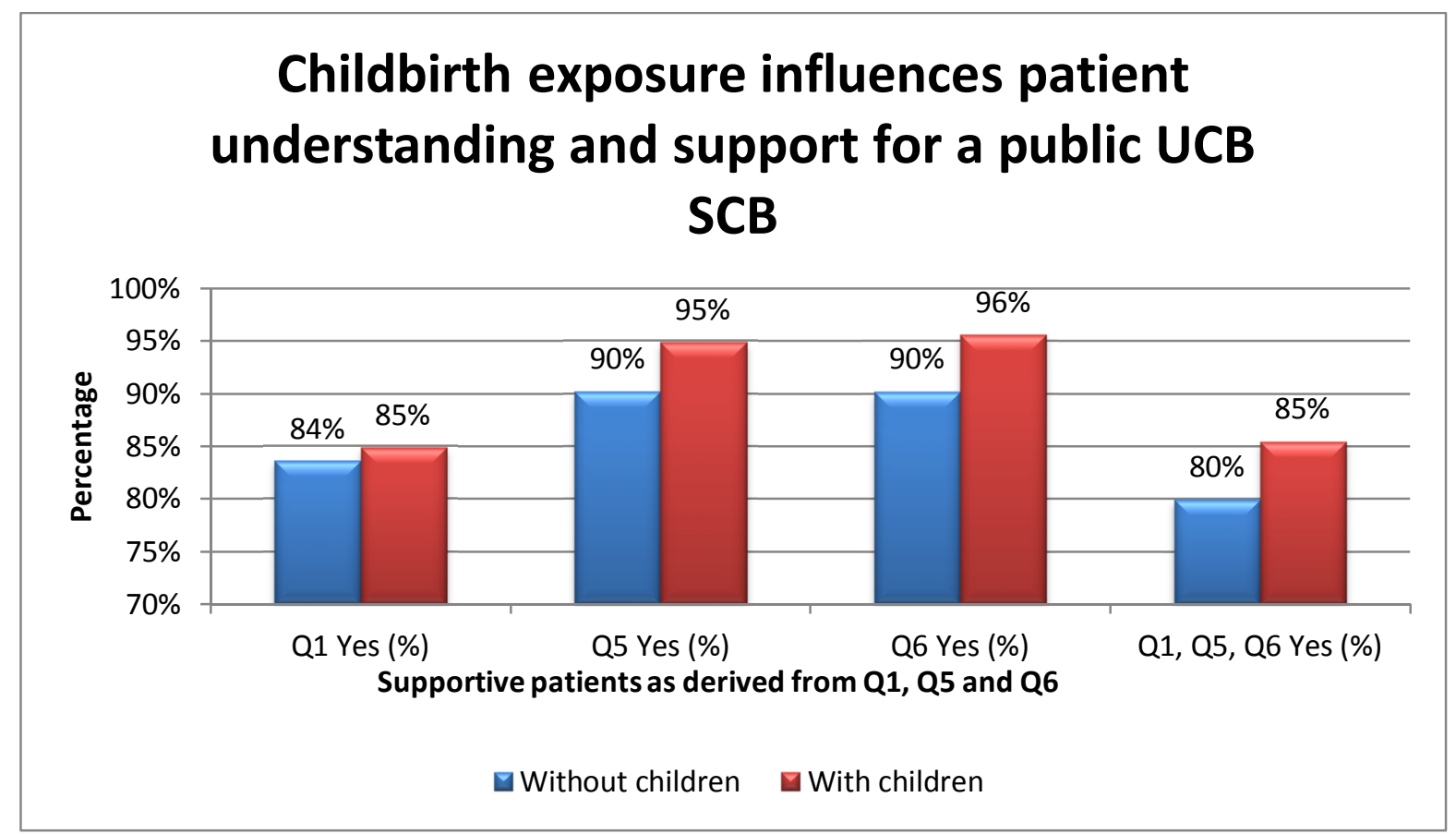


Figure 9

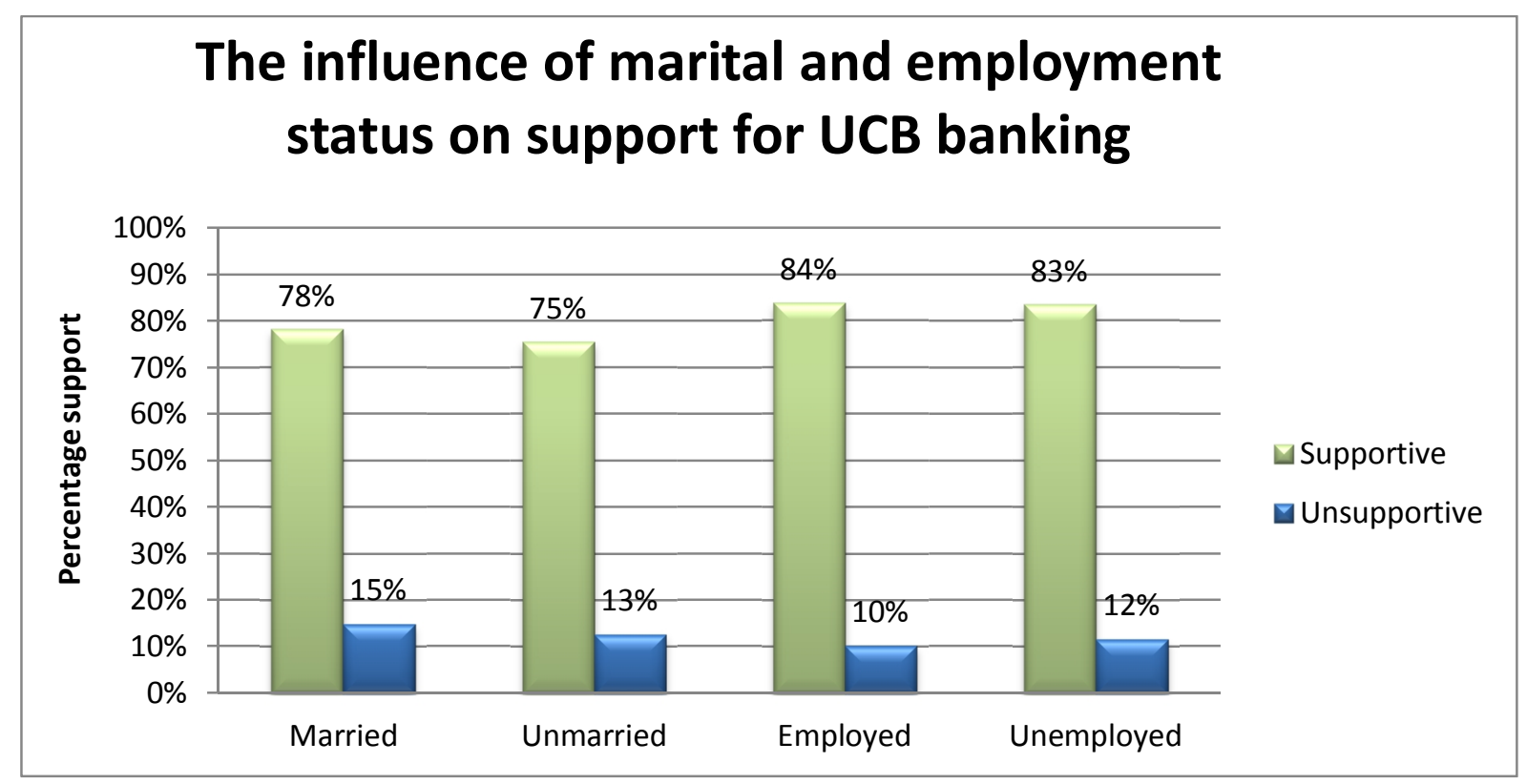

